DOI 10.37882/2500-3682.2021.02.02

\title{
НАРУШЕНИЕ ПИЩЕВОГО ПОВЕДЕНИЯ И ТОЛЕРАНТНОСТЬ К СТРЕССУ
}

\section{EATING DISORDER AND STRESS TOLERANCE}

\section{E. Bobrovskaya}

Summary: The article examines the influence of stress factors and stress tolerance on the formation of eating disorders based on the analysis of modern domestic and foreign studies. Eating disorders (including anorexia nervosa and bulimia nervosa, food addiction) are manifested in the rewarding function of eating in a situation of overeating or fasting. The formation of food addiction is influenced by biological, social and psychological factors. Food addiction can be viewed as a maladaptive conflict resolution strategy. Stress tolerance (stress tolerance, stress resistance) is a person's ability to cope with stress factors. Resistance to stress is manifested as the ability to socially adapt and be active in a stressful situation. People with eating disorders are characterized by difficulty regulating emotional states, a predominance of coping avoidance strategies, a deficit in problem-solving strategies, an inability to accept social support, and the use of maladaptive cognitive schemas.

Keywords: eating disorder, food addiction, stress, coping behavior.
$\mathrm{P}$ асстройства пищевого поведения являются актуальной медико-психологической проблемой во многих странах мира. При этом меры профилактики и коррекции, направленные на решение проблемы пищевых зависимостей, часто имеют лишь временный эффект, так как при их разработке не учитываются психологические факторы формирования аддиктивного поведения. Повышенная стрессогенность современного образа жизни безусловно оказывает влияние на формирование картины пищевых нарушений, так как пищевое поведение в целом поддается влиянию внешних стрессовых воздействий. В условиях хронического стресса происходит потеря ощущения безопасности, происходит формирование и закрепление дезадаптивных стратегий поведения.

\section{Научная новизна}

Несмотря на то, что исследования поведения человека в ситуации стресса широко представлены в научной литературе, влияние стрессовых факторов на риск развития нарушений пищевого поведения недостаточно представлено в современных работах. Анализ зарубежных исследований за последние годы имеет важное теоретическое и практическое значение для разработки
Бобровская Елена Фаимовна

Аспирант, Новосибирский Государственный Университет Экономики и Управления babrovskayae@mail.ru

Аннотация: В статье рассматривается влияние стрессовых факторов и толерантности к стрессу на формирование расстройств пищевого поведения на основе анализа современных отечественных и зарубежных исследований. Расстройства пищевого поведения (включая нервную анорексию и булимию, пищевые аддикции) проявляются в подкрепляющей функции еды в ситуации переедания или голодания. На формирование пищевой аддикции оказывают влияние биологические, социальные и психологические факторы. Пищевая аддикция может быть рассмотрена как дезадаптивная стратегия разрешения конфликтов. Толерантность к стрессу (стресс-толерантность, стрессоустойчивость) представляет собой способность человека совладать со стрессогенными факторами. Стрессоустойчивость проявляется как способность к социальной адаптации и активности в ситуации стресса. Для людей с расстройствами пищевого поведения характерны затруднения в регулировании эмоционального состояния, преобладание копинг-стратегии избегания, дефицит стратегии разрешения проблем, неспособность принимать социальную поддержку и использование неадаптивных когнитивных схем.

Ключевые слова: нарушение пищевого поведения, пищевая аддикция, стресс, совладающее поведение.

программ профилактики пищевых аддикций и работы с группами риска.

Пищевое поведение представляет собой ценностное отношение человека к употреблению еды, некий стереотип потребления пищи в стандартных и стрессовых условиях. Пищевое поведение - это установки, поведенческие стратегии, привычки, связанные с пищей и те специфические эмоции, которые она вызывает [1]. В зависимости от многих факторов, в том числе и психологических, пищевое поведение может принимать адекватную или девиантную форму.

Расстройства пищевого поведения (включая нервную анорексию и булимию, пищевые аддикции) проявляются в подкрепляющей функции еды в ситуации переедания или голодания. На формирование пищевой аддикции оказывают влияние биологические, социальные и психологические факторы [1].

Нарушения пищевого поведения (или пищевые аддикции) могут быть представлены в следующих видах.

Нервная анорексия - это расстройство, характеризующееся отказом от пищи с целью поддержания желае- 
мой физической формы, что часто вызвано неприятием собственного тела, приводящее к истощению организма (иногда с летальным исходом) вследствие голодания.

Булимия - это состояние, характеризующееся приступами неуправляемого аппетита, потерей контроля над процессом приема пищи, попытками избавиться от съеденного [1].

Среди наиболее распространенных причин нарушений пищевого поведения можно выделить следующие:

- Личностные особенности (эмоциональная лабильность, низкая самооценка, ориентация на мнение окружающих, чувство вины);

- Пищевые привычки семьи и близкого окружения, стиль воспитания;

- Общественные представления об идеале внешнего вида;

- Наследственная предрасположенность;

- Психические расстройства (нарушения пищевого поведения часто наблюдаются при депрессии, шизофрении, биполярном аффективном расстройстве);

- Стресс (пищевое поведение как средство компенсации эмоционального напряжения) [1].

Пищевая зависимость может быть рассмотрена как дезадаптивная стратегия разрешения конфликтов. Пища, в таком случае, выступает в роли замещающего способа коммуникации с субъективным ощущением собственной несостоятельности, несоответствия. Это ощущение возникает вследствие невозможности установления эффективного контакта с окружающими. Пищевая аддикция, в таком случае, представляет собой стратегию совладающего поведения, при которой еда и физическая форма являются наиболее значимыми [4].

Пищевая аддикция представляет собой способ регуляции аффективного состояния, который строится на механизме «двойного пути», когда неудовлетворенность своим физическим состоянием и внешним обликом вызывает ограничивающее пищевое поведение, что приводит к депрессии и последующему перееданию [18].

При пищевой аддикции наиболее значимым объектом, полностью подконтрольным и безопасным для изменений, становится тело, его физическая форма и внешний вид. А контроль над весом дает замещающее ощущение контроля над собственной жизнью [6]. Хотя стресс является одним из наиболее частых триггеров переедания, работ, посвященных изучению реакции на стресс у людей с этим расстройством, достаточно мало. Исследуя литературу, посвященную этой проблеме, К. Нэш отмечает, что переедание имеет прямую связь с повышенной реакцией на стресс [11].
Для ситуации стресса характерно постоянное эмоциональное и психическое напряжение, что может вызвать нарушение обмена веществ и привести к формированию пищевых аддикций [17].

Понятие «стресс» впервые употребил У. Кэннон в1926 году в значении состояния высокого нервного напряжения, возникшего в результате сильного внешнего воздействия [14].

Г. Селье, продолжая работу У. Кэннона, определял стресс как неспецифическую реакцию организма на предъявленное ему требование среды [15]. Он ввел концепцию адаптационной энергии, которая позволила описать различные варианты распределения и объемы энергии адаптации в структурно-функциональной системе адаптации организма [16]. Адаптация является эволюционной системой реакции организма на стимулы среды, то есть перенаправления адаптационной энергии для устранения наиболее разрушительных воздействий.

Б. Голдстоун, развивая теорию Селье и признавая эффективность теории адаптационной энергии, установил, что адаптационная энергия не имеет заданного объема, как полагал Селье, а может восполняться и накапливаться [9].

Толерантность к стрессу (стресс-толерантность, стрессоустойчивость) представляет собой способность человека совладать со стрессогенными факторами. Стрессоустойчивость проявляется как способность к социальной адаптации и активности в ситуации стресса.

Многочисленные исследования поведенческих особенностей в ситуации стресса показали наличие копингстратегий или механизмов совладающего поведения, которые позволяют произвести успешную адаптацию в изменяющихся условиях жизни. Р. Лазарус и С. Фолкман выделили такие стратегии совладающего поведения как: разрешение проблем, избегание проблем и поиск социальной поддержки. Среди ресурсов совладающего поведения выделяют локус контроля, когнитивные ресурсы, позитивную Я-концепцию, эмпатию и аффилиацию [10].

С. Хобфолл описал следующие копинг-стратегии:

- ассертивное поведение;

- установление социального взаимодействия;

- поиск поддержки;

- агрессивное поведение;

- манипулятивные действия;

- осторожное поведение;

- импульсивное поведение;

- манипуляция, избегание [7]. 
Каплан и Шехтер (1957) установили, что некоторые люди реагируют на стрессовую ситуацию как на голод (увеличение объема потребляемой пищи), если не научились различать голод и тревогу. При этом некоторые не научаются определять некоторые физиологические сигналы (сокращения желудка, например) как признак голода, и в ситуации стресса потребление пищи снижается. Многочисленные исследования (Коннер и пр. 1999, Оливер и Уордл 1999) показали, что в условиях стресса человек увеличивает количество приемов пищи (перекусов), но снижает количество пищи, потребляемой в течение дня. Таким образом, стресс оказывает влияние на структуру питания, что может вызвать изменения в пищевом поведении [2].

Исследуя особенности стресс-совладающего поведения у подростков, склонных к зависимому поведению, М.Н. Усцева установила, что деструктивные копинг-стратегии (дефицит навыков стратегии «разрешения проблем», преобладание стратегии «избегания», неспособность принимать социальную поддержку) оказывают влияние на формирование аддиктивного поведения. При этом подросткам, склонным к аддикциям, в целом характерна более выраженная стратегия «поиска социальной поддержки» [3].

Проведенное исследование влияния йоги, как способа развития стрессоустойчивости и регулирования своего эмоционального состояния, на риск развития пищевой зависимости показал, что включение занятий йогой в лечебные и профилактические программы дает положительный эффект и риск развития пищевой зависимости значительно снижается. Исследователи объясняют этот эффект тем, что йога способствует развитию большей осознанности, наблюдательности и внимательности к своему физическому состоянию и потребностям, что положительно влияет на формирование адаптивных копинг-стратегий [12].

В результате исследования взаимосвязи между глобальными и специфическими способностями и стратегиями регуляции эмоций (конкретными способностями регуляции эмоций, такими как: эмоциональное осознание, эмоциональная ясность; и стратегиями: принятие эмоций, переоценка, решение проблем, размышление, избегание эмоций и подавление) и расстройствами пищевого поведения, было установлено, что для людей, страдающих расстройствами пищевого поведения характерны неадаптивные стратегии регуляции эмоций [13].

Была выявлена взаимосвязь между отсутствием эмоциональной осведомленности, ясностью, принятием, переоценкой, решением проблем и расстройствами пищевого поведения. Избегание эмоций и подавление также имели связь с нервной анорексией и нервной булимией. В целом регуляция эмоций не различалась при разных расстройствах пищевого поведения, что подтверждает трансдиагностический характер проблем регуляции эмоций при патологии пищевого поведения [13].

Отмечается, что пациенты с расстройствами пищевого поведения часто испытывают трудности с регулированием эмоционального состояния, что имеет взаимосвязь с толерантностью к стрессу, которая часто встречается у пациентов с импульсивными расстройствами. Однако элементы, которые составляют толерантность к стрессу, четко не определены, что затрудняет проведение реабилитационных мероприятий и составление программ помощи.

В результате исследования показателей толерантности к стрессу у людей, страдающих расстройствами пищевого поведения, было установлено следующее: люди с диагностированными расстройствами пищевого поведения показали более высокий уровень избегания аффекта, в то время как люди, не имевшие расстройств, имели более высокие баллы по шкале «Принятия и управления» [5].

Исследование взаимосвязи толерантности к стрессу, когнитивными схемами (эмоциональное торможение, дефектность / стыд, социальная изоляция и недостаточный самоконтроль) и риском развития расстройств пищевого поведения, проведённого на студентах показало, что неадаптивные когнитивные схемы проявляются при расстройствах пищевого поведения. Толерантность к стрессу опосредует ассоциации между конкретными схемами социальной изоляции и недостаточным самоконтролем, и риском расстройства пищевого поведения. Эти результаты предоставляют предварительные доказательства того, что определенные когнитивные схемы могут способствовать снижению толерантности к стрессу, что увеличивает риск развития нарушений пищевого поведения [8].

\section{Зак^ючение}

В результате анализа исследований взаимосвязи стресса толерантности к стрессу и расстройствами пищевого поведения было установлено, что в условиях стресса человек может увеличивать количество приемов пищи, но снижать само количество потребляемой пищи. Стресс оказывает влияние на структуру питания, что может вызвать изменения в пищевом поведении. Пациенты с расстройствами пищевого поведения часто испытывают трудности с регулированием эмоционального состояния, что имеет взаимосвязь с толерантностью к стрессу, показывают более высокий уровень избегания аффекта и использование неадаптивных когнитивных 
схем. Толерантность к стрессу опосредует ассоциации между конкретными схемами социальной изоляции и недостаточным самоконтролем, и риском расстройства пищевого поведения. Исследователями была выявлена взаимосвязь между отсутствием эмоциональной осведомленности, ясностью, принятием, переоценкой, решением проблем и расстройствами пищевого поведения. Избегание эмоций и подавление также имели связь с нервной анорексией и нервной булимией, а деструктивные копинг-стратегии (дефицит навыков стратегии разрешения проблем, преобладание стратегии избегания, неспособность принимать социальную поддержку) оказывают влияние на формирование адиктивного поведения.
Представляется важным изучение как дезадаптивных, так и адаптивных стратегий совладания со стрессом при расстройствах пищевого поведения. Стратегии формирования толерантности к стрессу должны быть направлены как на снижение активности использования стратегии избегания, так и на развитие навыков управления эмоциями.

Результаты исследования могут быть использованы в профилактике, диагностике и коррекции аддиктивного поведения. Своевременная диагностика позволит прогнозировать формирование определенных личностных особенностей, в том числе копинг-стратегий, способствующих формированию расстройств пищевого поведения.

\section{ЛИТЕРАТУРА}

1. Менделевич, В.Д. Руководство по аддиктологии. СПб.: Речь, 2007. 768 с.

2. Петров Г.Д. Влияние стресса на пищевое аддиктивное поведение. Проблемы эффективного использования научного потенциала общества. Сборник статей Международной научно-практической конференции. Уфа: МЦИИ «ОМЕГА САЙНС». 2017. С. 262-264.

3. Усцева М.Н. Особенности стресс-совладающего поведения подростков с аддиктивным и неаддиктивынм поведением. Проблемы современного педагогического образования. 2020. № 66-1. С. 344-347.

4. Axtell A., Neulon B. Analysis of Adlerian life themes of bulimic women. Individ. Psychol. 1993. № 1. P. 58-67.

5. Corstorphine E., Mountford V., Tomlinson S., Waller. G., Meyer C. Distress tolerance in the eating disorders. Eating Behaviors. V. 8, I. 1. 2017. P. 91-97.

6. Dozier M., K. Chase Stoval, Kathleen E. Albus. Attachment and Psychopathology in adulthood. Handbook of attachment: Theory, research, and clinical applications, 2008. P. 718-744.

7. Hobfoll S. Conservation of resources: A new attempt at conceptualizing stress. American psychologist 44 (3). 1989. P. 513.

8. Hovrud L., Simons R., Simons J. Cognitive Schemas and Eating. Disorder Risk: the Role of Distress Tolerance. International Journal of Cognitive Therapy. Springer. V. 13. 2020. P. 54-66.

9. Goldstone B., The general practitioner and the general adaptation syndrome, S. Afr. Med. J. 26 (1952). P. 106 — 109.

10. Lazarus R., Folkman S. Stress, appraisal and coping. New York: Springer.1984. P. 445.

11. Naish K., Laliberte M., MacKillop J., Balodis I. Systematic review of the effects of acute stress in binge eating disorder. Special Issue: Addiction. V. 50, I.3. 2019. P. 2415-2429.

12. Pacanowski C., Diers L., Crosby R., Neumark-Sztainer D. Yoga in the treatment of eating disorders within a residential program: A randomized controlled trial. Eat Disord. 25(1), 2017, P. 37-51.

13. Preft A., Candea D., Szentagotai-Tatar A. Emotion regulation across eating pathology: A meta-analysis. Appetite. V. 143. 2019. P. 143-151.

14. Quick J. C., C. D. Spielberger, Walter Bradford Cannon: Pioneer of stress research, International Journal of Stress Management, V.1, N.2, 1994. P. 141 — 143.

15. Selye H., Experimental evidence supporting the conception of «adaptation energy», Am. J. Physiol. 123 (1938), 758 — 765.

16. Selye, H. Stress in health and disease. Boston: Butterworths. 1976. P. 226.

17. Schkade, J.K., \& Schultz, S. Occupational adaptation. In P. Kramer, J. Hinojosa, \& C.B. Royeen (Eds.), Perspectives in human occupation: Participation in life. 2003. P. 181- 221.

18. Slice E. A prospective test of the dual-pathway model of bulimic pathology: mediating effects of dieting and negative affect // J. Abnorm. Psychol. 2001. Vol. 110. № 1. P. 124-135. 